\title{
Long days, long trips: foraging ecology of female rockhopper penguins Eudyptes chrysocome chrysocome at Tierra del Fuego
}

\author{
Adrián Schiavini*, Andrea Raya Rey \\ Consejo Nacional de Investigaciones Científicas y Técnicas, Centro Austral de Investigaciones Científicas, \\ Bernardo Houssay 200, (V9410BFD) Ushuaia, Tierra del Fuego, Argentina
}

\begin{abstract}
In rockhopper penguins Eudyptes chrysocome, the relationship between foraging effort and the daylight period is unclear. We studied the foraging ecology of female southern rockhoppers that were brooding chicks at Bahía Franklin (Staten Island) in December 2000. We compare our data with data presented for other subspecies and locations, analyzing the features of their foraging ecology and its relationship with the daylight period around Staten Island, the population size of different breeding locations and the marine environment. Southern rockhopper penguins performed longer trips (about 30 and $60 \%$ longer for daily and overnight trips respectively) and between 5 and 7 more overnight trips (53\%) than the northern and eastern subspecies. Mean dive depth and dive duration were $28.9 \pm 24.6 \mathrm{~m}$ and $79 \pm 30 \mathrm{~s}$ respectively. The diving rate $\left(30.4 \pm 5.0\right.$ dives $\left.\mathrm{h}^{-1}\right)$, and the proportion of trip duration underwater $(66.2 \pm 5.9 \%)$ confirmed the high foraging effort of rockhopper penguins. During the study period foraging trip duration increased, but dive parameters did not vary. Penguins traveled as much as $20 \mathrm{~km}$ to their foraging waters, either in shelf waters and/or in waters of a close shelf-break and slope. The diet was dominated in numbers by euphausiids, amphipods, cephalopods, fish larvae and juveniles, all prey species commonly found in Subantarctic waters. The long trips could be explained by the long twilight period and by diel vertical migration of prey, confirming the phenotypic plasticity of penguins in response to different marine environments. The extended foraging trip duration may contribute to sustaining the high level of the breeding population (167 000 breeding pairs) at Bahía Franklin, and account for differences in the recent history of different breeding colonies in the SW Atlantic Ocean.
\end{abstract}

KEY WORDS: Eudyptes chrysocome chrysocome - Southern rockhopper penguin · Foraging ecology • Diving behavior · Diet · Tierra del Fuego $\cdot$ SW Atlantic Ocean

Resale or republication not permitted without written consent of the publisher

\section{INTRODUCTION}

Penguins constitute a large proportion of the top predator biomass in subantarctic and antarctic waters (Croxall 1984, Croxall \& Lishman 1987). During the breeding time, when birds congregate in colonies and parents must provide food for both their offspring and themselves, foraging activity may be particularly great close to colonies. The rockhopper penguin Eudyptes chrysocome is one of the most abundant penguin species, and also the second smallest penguin species. The southern subspecies E. chrysocome chrysocome (here- after referred to as chrysocome) breeds in southern South America and the Falkland (Malvinas) Islands. Staten Island, at the eastern tip of the Tierra del Fuego archipelago, holds 174000 breeding pairs (26\% of the breeding population of this subspecies), with 167000 nests located in a large colony recently discovered in Bahía Franklin (Schiavini 2000).

The diving and foraging behavior of rockhopper penguins during the brooding period has been studied in detail by Cherel et al. (1999) and by Tremblay \& Cherel $(1999,2000,2003)$ at Amsterdam, Crozet and Kergue- 
len Islands, and by Hull (2000) at Macquarie Island. The behavior described suggests that daylight duration represents a limiting factor as, in general, females make daily foraging trips, leaving the colony by dawn and returning by dusk. Cherel et al. (1999) and Tremblay \& Cherel (2003) recorded high dive frequencies and percentage of trip duration underwater, concluding that brooding females operate at a high level of foraging effort, with little scope for increasing effort by an increase in the percentage of time underwater. They also suggested that foraging trip duration is the most likely foraging behavior characteristic of female rockhopper penguins that would vary during the brooding period. Despite these mentioned studies, the relationship between trip duration, foraging effort and daylight duration in rockhopper penguins remains unclear.

The Tierra del Fuego archipelago is one of the southernmost breeding areas of the species, with an extended daylight period during the breeding season compared to other breeding locations. By studying the foraging ecology in an area in which the daytime period is long and comparing the results with data for other localities, we explored the relationship between trip duration, foraging effort and daylight duration. Given the behavioral plasticity of the species (Tremblay \& Cherel 2003) we hypothesize that, under longer daylight periods, foraging effort (as time spent underwater) decreases, but trip duration increases.

Ashmole (1963) proposed that pelagic seabird populations are limited by density-dependent competition for food around their breeding colonies. Cairns (1989) proposed that colony population size is a function of the size of the foraging habitat. The large size of the chrysocome colony on Staten Island raises questions about the levels of intraspecific competition that these birds would potentially experience. During the brooding period only the females feed the chicks, and their foraging range is constrained, increasing the potential for competition with other breeders, juveniles and failed breeders. In comparing the foraging behavior among different locations with different population sizes, it would be expected that larger rockhopper breeding colonies would tend to exploit farther foraging grounds or forage over longer periods than smaller populations.

This is the first report of the foraging ecology of female southern rockhopper penguins in the SW Atlantic Ocean during the brooding period. The large population size and location of the colony at Bahía Franklin, Staten Island, enabled us to investigate factors influencing the foraging ecology of rockhopper penguins. We compare our data with data presented for other subspecies and locations, i.e. northern rockhopper penguins Eudyptes chrysocome moseleyi (hereafter referred to as moseleyi) and eastern rock- hooper penguin E. chrysocome filholi (hereafter referred to as filholi), analyzing the relationship between their foraging ecology, the daylight period, the population size at the different breeding locations and the marine environment around Staten Island.

\section{MATERIALS AND METHODS}

Study site. Fieldwork was undertaken at Bahía Franklin, Staten Island, Tierra del Fuego (54 $50.0^{\prime} \mathrm{S}$, $64^{\circ} 40.5^{\prime} \mathrm{W}$, Fig. 1). Staten Island is situated at the southern extreme of the Patagonian shelf, where the $200 \mathrm{~m}$ isobath is located $12 \mathrm{~km}$ from the southern coast of Staten Island (Servicio de Hidrografía Naval 1993). Bahía Franklin is an open rectangular bay with a square mouth of $5.5 \mathrm{~km}$ width. It faces the Le Maire Strait, a $30 \mathrm{~km}$ wide passage that separates Staten Island from the Isla Grande de Tierra del Fuego. The sediments of the Le Maire Strait comprise sand, gravel and mud (Parker et al. 1997). The strait is famous for its strong tidal currents (up to 4 knots in the main axis) that interact with the Falkland (Malvinas) current, as well as with the prevailing western winds. Tide-rips and whirlpools are very common inshore close to headlands and points.

The waters around Staten Island are in the Subantarctic Zone, with the Subantarctic Front occurring at about $80 \mathrm{~km}$ SE of Staten Island (Orsi et al. 1995). Local oceanography includes waters from the Antarctic Circumpolar Current that generates the Falklands (Malvinas) Current after passing the Drake Passage, as well as shelf waters affected by continental discharges and tidal fronts (Sánchez et al. 1995, Bertolotti et al. 1996, Piola \& Rivas 1997). To the east of Staten Island $(110 \mathrm{~km})$, waters are influenced by a shelf-break front, an area recognized to be of high productivity (González et al. 1997). Waters off Tierra del Fuego and Staten Island contain important biomasses of zooplankton and ichthyoplankton (Sánchez \& Ciechomski 1995, Sabatini et al. 1999, 2001).

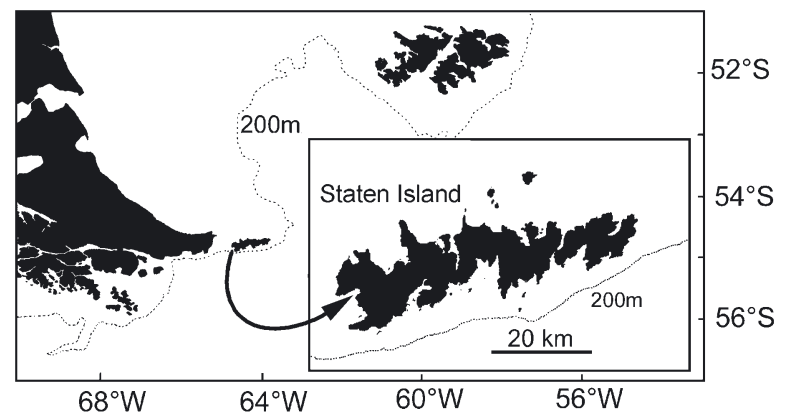

Fig. 1. Southern portion of SW Atlantic Ocean, showing location of study site 
Instrument deployment. We equipped 11 females with 3 time-depth recorders (TDRs) from December 6 to 16,2000 , during the second half of the guard period (chicks started to hatch on November 27). At this time only the female provides food for the chick, while the male guards the nest. We used Lotek LTD-100 TDRs, also equipped with light sensors, to collect dive data. The devices had a 'nose-drop' shape to reduce hydrodynamic drag, presented a cylindrical section, measured $61 \times 18 \mathrm{~mm}$ and weighed $16 \mathrm{~g}$ in air, corresponding to $<2 \%$ of the cross-sectional area of the birds and $<1 \%$ of their body mass. We deployed 3 devices consecutively on 11 females. TDRs were attached using Tesa ${ }^{\circledR}$ tape as described by Wilson et al. (1997a). The devices were deployed for $2.7 \pm 0.8 \mathrm{~d}$ (range 1.8 to $3.8 \mathrm{~d}$ ). During the first deployments we left the devices on the penguins for only 1 or $2 \mathrm{~d}$, in the belief that penguins performed daily foraging trips. When we noticed that the birds stayed in the water overnight, we deployed devices for longer periods. TDRs were programed to sample depth and light continuously at $2 \mathrm{~s}$ sampling intervals, allowing a total recording time of $6 \mathrm{~d}$ deploy $^{-1}$.

Diet analysis. Diet sampling was conducted using the water-offloading technique (Wilson 1984) on 11 females. For 4 birds, stomach samples were collected after recovering the TDRs. Birds were captured at the nest after display with their partner prior to deliver the food to chicks, weighed, sexed using bill depth and length, and lavaged. Diet samples were drained and preserved with $70 \%$ ethanol. In the laboratory, samples were weighted and sorted into the main components: fishes, squid and crustaceans. A subsample of $1 / 8$ of each sample was analyzed, and the results were extrapolated to the total. Identification of taxa was made using entire specimens for crustaceans, lower beaks for cephalopods and otoliths and cranial bones for fishes, and comparing them with the literature and our reference collection. Diet is described in terms of percentage frequency of occurrence, percentage by number and percentage by mass, to allow for the various biases of each of these techniques (Hyslop 1980, Duffy \& Jackson 1986). The original weight of specimens ingested was estimated by applying regression equations relating squid beak size (lower rostral length) and euphausid standard body length (anterior edge of eyeball to tip of telson) to body mass (Clarke 1986, Ridoux 1994).

Data analysis. We analyzed dive data using MULTITRACE (Jensen Software Systems). Data were corrected for a drifting surface level. A dive was deemed to occur when the maximum dive depth was $\geq 3 \mathrm{~m}$ (after Chappel et al. 1993, 1999, Tremblay \& Cherel 2000, 2003). For each dive, the software calculated duration, onset, maximum depth, pre-dive interval (from which we derived post-dive interval), bottom time (time spent at $75 \%$ of maximum dive depth attained during the dive: after Cherel et al. 1999, Tremblay \& Cherel 2000, 2003), descent rate (from beginning of dive to start of bottom phase), and ascent rate (from end of bottom phase to end of dive). Vertical travel distance (VTD) was defined as 2 times the sum of the maximum dive depth for all dives performed during each trip (Horning \& Trillmich 1997). Diving efficiency (proportion of bottom time over a complete dive cycle) was estimated following Ydenberg \& Clark (1989) as diving efficiency = bottom time/(dive duration + post-dive interval). We compared our dive data with those reported by Hull (2000) in only a broad sense, as she considered dives $>6 \mathrm{~m}$ depth for her analysis and her data for the 'chick rearing' period were pooled among sexes and included both the brooding and crèche period. We considered dives $\leq 5 \mathrm{~m}$ depth as traveling dives and dives $>5 \mathrm{~m}$ depth as foraging dives, after Tremblay \& Cherel (2003).

We assessed temporal changes in several parameters of foraging and diving behavior, considering the time elapsed since the first day of hatching (November 27) to the median point of each foraging trip as the independent variable (the date of hatching for chicks from to the studied females could not be recorded). We determined if an individual equipped with a TDR was either on land or in the water by the light-sensor readings: it was deemed to be on land when the readings presented a smooth profile, and to be resting on the sea surface when the readings presented an erratic profile (which we assumed represented movements of the penguins on the water surface). We confirmed this assumption with readings from individuals equipped with TDRs and also with implanted glass-encapsulated microchips with individual identification numbers (transponders, TIRIS $23 \mathrm{~mm}$, Texas Instruments ${ }^{\circledR}$ ), which were simultaneously detected by an automatic reading system.

Successive dive data are partially autocorrelated, as the maximum depth of a dive is influenced by the previous depths attained. As a consequence, data are temporally pseudoreplicated (Hurlbert 1984). To overcome this we followed the method of Tremblay \& Cherel (2003). We performed a partial autocorrelation analysis, which verified that maximum dive depth failed to correlate after 4 successive dives. Thus, remaining 1 dive out of 4 would reduce the autocorrelation. On the other hand, all birds do not have the same statistical weight because of the unequal number of trips and of dives per trip recorded for the different individuals. Therefore, when examining dive parameters, we considered the bird as the sample unit and not the trip. Since the trip with the lowest number of dives contained 262 dives, we sampled 65 dives per 
Table 1. Eudyptes chrysocome. Summary of foraging trip and dive characteristics for different subspecies of female rockhopper penguins at different localities. Values are means \pm SD. nr: not reported

\begin{tabular}{|c|c|c|c|c|c|}
\hline Dive depth & $\begin{array}{l}\text { Staten Island } \\
\text { ssp. chrysocome } \\
\text { (this paper) } \\
\quad \geq 3 \mathrm{~m}\end{array}$ & $\begin{array}{l}\text { Macquarie Island } \\
\text { ssp. filholi } \\
\text { (Hull 2000) } \\
>6 \mathrm{~m}\end{array}$ & $\begin{array}{l}\text { Amsterdam Island } \\
\text { ssp. moseleyi } \\
\text { (Tremblay \& } \\
\text { Cherel 2003) } \\
>5 \mathrm{~m}\end{array}$ & $\begin{array}{c}\text { Kerguelen Island } \\
\text { ssp. filholi } \\
\text { (Tremblay \& } \\
\text { Cherel 2003) } \\
\text { >5 m }\end{array}$ & $\begin{array}{l}\text { Crozet Island } \\
\text { ssp. filholi } \\
\text { (Tremblay \& } \\
\text { Cherel 2003) } \\
\quad>5 \mathrm{~m}\end{array}$ \\
\hline \multicolumn{6}{|l|}{ Trip duration (h) } \\
\hline Day trips & $\begin{array}{c}15.7 \pm 5.1 \\
(\mathrm{n}=7)\end{array}$ & $\begin{array}{c}153.4 \pm 108.0 \\
(\mathrm{n}=7)^{\mathrm{a}}\end{array}$ & $\begin{array}{l}12.2 \pm 2.57 \\
(\mathrm{n}=107)\end{array}$ & $\begin{array}{c}11.9 \pm 2.0 \\
(\mathrm{n}=123)\end{array}$ & $\begin{array}{c}11.2 \pm 3.6 \\
(\mathrm{n}=125)\end{array}$ \\
\hline Overnight trips & $\begin{array}{c}34.8 \pm 8.7 \\
(\mathrm{n}=7)\end{array}$ & & $\begin{array}{c}35.6 \pm 6.6 \\
(\mathrm{n}=12)\end{array}$ & - & $28.6 \pm 5.0(n=13)$ \\
\hline Overnight trips (\%) & $53 \%(\mathrm{n}=15)$ & $\mathrm{nr}$ & $11 \%(n=119)$ & - & $10 \%(n=138)$ \\
\hline \multicolumn{6}{|l|}{ Outward travel time $(\mathrm{h})$} \\
\hline Day trips & $1.12 \pm 0.92$ & $\mathrm{nr}$ & $0.51 \pm 0.29$ & $0.21 \pm 0.30$ & $0.41 \pm 0.45$ \\
\hline Overnight trips & $1.10 \pm 0.39$ & & $0.57 \pm 0.26$ & - & $0.58 \pm 0.57$ \\
\hline \multicolumn{6}{|l|}{ Inward travel time $(\mathrm{h})$} \\
\hline Day trips & $0.62 \pm 0.39$ & $\mathrm{nr}$ & $0.56 \pm 0.40$ & $0.69 \pm 0.85$ & $0.38 \pm 0.44$ \\
\hline Overnight trips & $0.79 \pm 0.78$ & & $0.43 \pm 0.19$ & - & $1.04 \pm 1.84$ \\
\hline \multicolumn{6}{|l|}{ No. of traveling dives } \\
\hline Day trips & $53 \pm 34$ & $\mathrm{nr}$ & $96 \pm 73$ & $57 \pm 73$ & $51 \pm 67$ \\
\hline Overnight trips & $103 \pm 54$ & & $210 \pm 109$ & - & $226 \pm 116$ \\
\hline \multicolumn{6}{|l|}{ No. of foraging dives } \\
\hline Day trips & $452 \pm 146$ & $\mathrm{nr}$ & $362 \pm 129$ & $292 \pm 69$ & $247 \pm 76$ \\
\hline Overnight trips & $882 \pm 254$ & & $913 \pm 221$ & - & $518 \pm 99$ \\
\hline \multicolumn{6}{|l|}{ Dive rate (dives $\mathrm{h}^{-1}$ ) } \\
\hline Day trips & $32.7 \pm 5.7$ & $14.8 \pm 9.4^{\mathrm{a}}$ & $37.2 \pm 9.5$ & $29.6 \pm 8.9$ & $27.1 \pm 5.9$ \\
\hline Overnight trips & $28.0 \pm 2.0$ & & $31.2 \pm 4.7$ & - & $26.2 \pm 3.9$ \\
\hline Maximum dive depth (m) & $28.9 \pm 24.6$ & $27.3 \pm 20.3$ & $22.5 \pm 15.7$ & $29.1 \pm 14.1$ & $40.4 \pm 17.6$ \\
\hline Deepest dive (m) & 113 & 104 & 93 & 85 & 104 \\
\hline \multicolumn{6}{|l|}{ Vertical travel distance $(\mathrm{km})$} \\
\hline Day trips & $27.80 \pm 14.24$ & $\mathrm{nr}$ & $16.02 \pm 3.97$ & $17.38 \pm 4.68$ & $20.06 \pm 7.47$ \\
\hline Overnight trips & $59.96 \pm 17.83$ & & $35.27 \pm 4.66$ & - & $39.50 \pm 8.83$ \\
\hline \multicolumn{6}{|l|}{ Dive time (\% trip duration) } \\
\hline Day trips & $68.9 \pm 5.2(n=7)$ & $36.6 \pm 9.3^{\mathrm{a}, \mathrm{b}}$ & $63.9 \pm 8.1$ & $61.9 \pm 8.8$ & $64.2 \pm 8.5$ \\
\hline Overnight trips & $63.4 \pm 5.7(\mathrm{n}=7)$ & & $49.7 \pm 3.9$ & - & $26.2 \pm 3.9$ \\
\hline Dive duration (s) & $79 \pm 30$ & $72 \pm 42$ & $78.4 \pm 34.8$ & $87.4 \pm 26.2$ & $101.0 \pm 27.0$ \\
\hline Post-dive interval (s) & $20 \pm 11^{\mathrm{c}}$ & $\mathrm{nr}$ & $25.2 \pm 15.1$ & $33.3 \pm 15.3$ & $36.0 \pm 17.5$ \\
\hline Bottom time (s) & $35 \pm 17$ & $30 \pm 6$ & $41.8 \pm 20.8$ & $54.7 \pm 20.8$ & $57.4 \pm 19.1$ \\
\hline Diving efficiency & $0.34 \pm 0.14^{\mathrm{c}}$ & $\mathrm{nr}$ & $0.40 \pm 0.13$ & $0.45 \pm 0.12$ & $0.42 \pm 0.11$ \\
\hline Descent rate $\left(\mathrm{m} \mathrm{s}^{-1}\right)$ & $1.2 \pm 0.5$ & $1.2 \pm 0.2$ & $1.1 \pm 0.5$ & $1.6 \pm 0.5$ & $1.7 \pm 0.6$ \\
\hline Ascent rate $\left(\mathrm{m} \mathrm{s}^{-1}\right)$ & $0.8 \pm 0.5$ & $1.0 \pm 0.2$ & $0.9 \pm 0.5$ & $1.3 \pm 0.5$ & $1.3 \pm 0.5$ \\
\hline Sample size & 520 & 57130 & 1632 & 1622 & 1693 \\
\hline
\end{tabular}

bird randomly. The resulting set (520 dives) was used to analyze the dive characteristics.

We estimated the distance traveled from the colony to where a penguin started to forage as the time elapsed between the initial dive to the first of the first 3 consecutive dives $\geq 10 \mathrm{~m}$ depth (after Cherel et al. 1999). We assumed that penguins travel continuously at a constant speed of $7.4 \mathrm{~km} \mathrm{~h}^{-1}$ (Brown 1987) and in a straight line. We estimated the return journey as the time elapsed between the last 3 consecutive dives $\geq 10 \mathrm{~m}$ depth and the final dive. The time of sunrise and sunset at the deployment locations were (for the mean date of device deployment on December 12) 04:35 and 21:49 h respectively (local time $=$ GMT $-3 \mathrm{~h}$ ), giving a solar day length of $16.75 \mathrm{~h}$. Dawn and dusk were at 01:28 and 01:00 $\mathrm{h}$ respectively following the nautical 
definition, i.e. when the sun is $12^{\circ}$ below the horizon. Thus, the twilight period (dawn and dusk together) lasted $6.78 \mathrm{~h}$ and nighttime was restricted to $0.47 \mathrm{~h}$ (28 $\mathrm{min})$. The common names we use for the rockhopper subspecies follow the nomenclature of Ellis et al. (1998). All mean values are presented with \pm SD.

\section{RESULTS}

\section{Trip characteristics}

Depth and light data indicated that either 1 female did not return or its device was lost, and that 2 other females did not leave the colony. Data were thus obtained from 8 females during 15 foraging trips that included 11819 dives performed during $390.3 \mathrm{~h}$ at sea. As 1 female was already in the water when the TDR started recording (at 00:00 h on December 10), its data was considered only for analysis of dive characteristics.

Of the foraging trips, 8 (53\%) included overnight foraging, and 1 of these included 2 nights at sea. The duration of the foraging trips (excluding the incomplete trip) averaged $25.3 \pm 12.0 \mathrm{~h}$. Daily trips differed from overnight trips in duration $(15.7 \pm 5.1 \mathrm{~h}, \mathrm{n}=7$ vs $34.8 \pm 8.7 \mathrm{~h}, \mathrm{n}=7$ respectively; Student's $t$-test, $t_{9}=$ 5.00, $\mathrm{p}=0.001$; Table 1$)$. Most departures $(71 \%, \mathrm{n}=14)$ occurred between 01:00 and 05:00 h, with a peak between 03:00 and 04:00 h $(43 \%, \mathrm{n}=14)$. Arrival times occurred between 10:00 and 24:00 h, with $47 \%$ of them between 10:00 and 19:00 $\mathrm{h}$ and with a peak between 23:00 and 24:00 h $(27 \%, \mathrm{n}=15)$. There was no difference in departure and arrival times between birds performing daily and overnight trips ( $t$-test, departure times, $t_{12}=-1.20, \mathrm{p}=0.21$; arrival times, $t_{13}=2.11, \mathrm{p}=$ $0.05)$. Periods on land (assessed for 7 trips) averaged $4.4 \pm 1.9 \mathrm{~h}$, with 4 stays during hours of darkness and 3 during daylight hours.

Travel time to foraging areas was $1.11 \pm 0.81 \mathrm{~h}(\mathrm{n}=$ 14 excluding the incomplete trip), and return time was $0.71 \pm 0.61 \mathrm{~h}(\mathrm{n}=15)$. Outward and inward traveling times were not significantly different $\left(t\right.$-test, $t_{13}=1.82$, $\mathrm{p}=0.09$ ) and did not differ between day and overnight trips ( $t$-test, outward trips, $t_{12}=0.91, \mathrm{p}=0.38$; inward trips, $\left.t_{11}=0.97, \mathrm{p}=0.35\right)$. Foraging ranges for the outward and return trips were estimated at $8.2 \pm 6.2$ and $5.3 \pm 4.6 \mathrm{~km}$ with maxima of 20.2 and $16.4 \mathrm{~km}$ respectively.

The number of dives $>3 \mathrm{~m}$ per foraging trip averaged $745 \pm 339$ and the average dive rate (based on trip duration) was estimated at $30.4 \pm 5.0$ dives $\mathrm{h}^{-1}$ (excluding the incomplete recorded trip with 1385 dives). Dive rate was $32.7 \pm 5.7$ and $28.0 \pm 2.0$ dives $\mathrm{h}^{-1}$ for daily and overnight trips respectively (Table 1 ) and were not significantly different $\left(t\right.$-test, $\left.t_{7}=2.05, \mathrm{p}=0.08\right)$. Dives made from dawn to dusk represented $99.6 \%$ of the 520 sampled dives. However, 121 of the sampled dives (23\%) were performed under twilight conditions.

\section{Dive characteristics}

Among the sampled dives that were $\geq 3 \mathrm{~m}$, the maximum dive depth was $113 \mathrm{~m}$ and the maximum dive duration was $164 \mathrm{~s}$. Average maximum dive depth was $28.9 \pm 24.6 \mathrm{~m}$, the frequency distribution of dive depth presented 1 peak between 4 and $6 \mathrm{~m}$ depth (13\%) and $50 \%$ of the dives were $\leq 19 \mathrm{~m}$ (Fig. 2). The mean proportion of foraging dives ( $>5 \mathrm{~m}$ depth) for all trips in chrysocome was $89.9 \pm 3.8 \%$ ( $\mathrm{n}=14$ excluding the incomplete trip).

Only 2 sampled dives were performed at night under the dawn and dusk times defined (reaching 5.4 and $6.1 \mathrm{~m}$ depth). During daylight hours, the mean maximum dive depth and its variation were relatively stable (Fig. 3), although maximum dive depths during twilight and night hours were shallow (Fig. 4). The mean dive duration was $79 \pm 30 \mathrm{~s}$, with $50 \%$ of the dives taking $\leq 78 \mathrm{~s}$. The frequency distribution presented 1 peak at 62 to $64 \mathrm{~s}$. Comparing twilight dives with daylight dives, twilight dives were shallower $(9.6 \pm 9.8$ vs $34.8 \pm$ $24.7 \mathrm{~m}, t$-test: $\left.t_{516}=10.96, \mathrm{p}<0.001\right)$, were shorter in dive duration $\left(57 \pm 21\right.$ vs $86 \pm 30 \mathrm{~s}, t$-test: $t_{516}=-9.75$, $\mathrm{p}<0.001$ ), and presented fewer foraging dives (>5 m depth) (76 vs $90 \%)$. The proportion of foraging dives (>5 m depth) per trip did not differ between day and overnight trips (Table 1) ( $t$-test: $t_{9}=-0.25, \mathrm{p}=0.8$ ).

Dive duration was positively related to dive depth (non-linear regression: duration $=[130.1 \times$ depth $] /$ [depth +11.5$], R^{2}=0.72$, Fig. 5a). Outliers represented

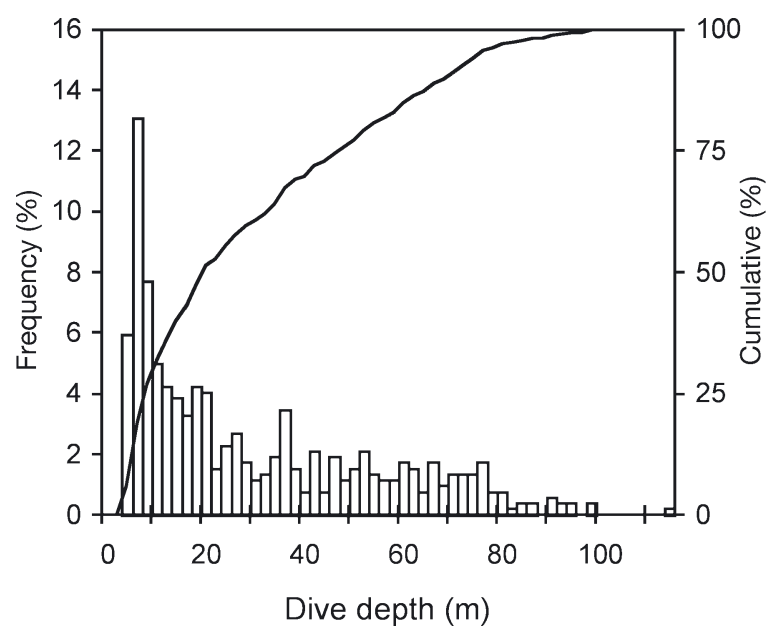

Fig. 2. Eudyptes chrysocome chrysocome. Frequency distribution of dive depth 


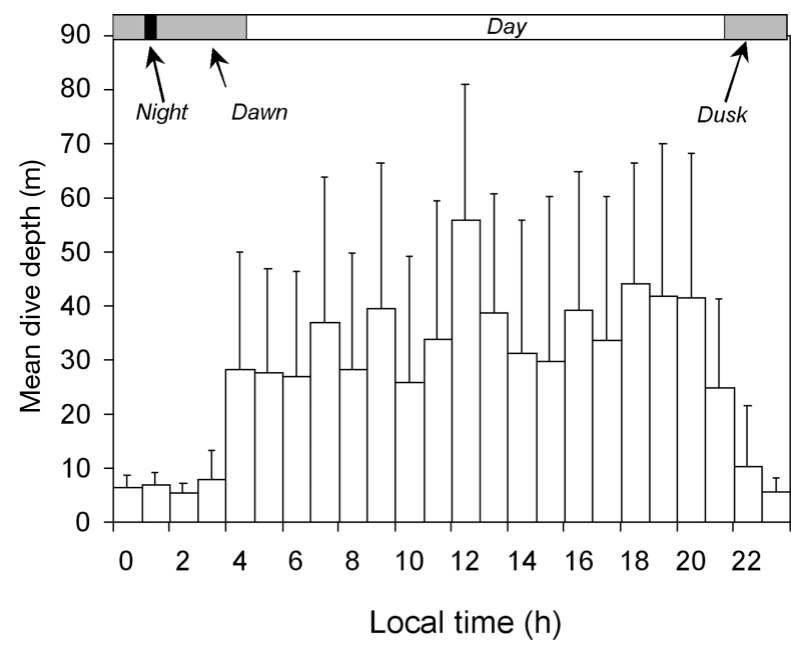

Fig. 3. Eudyptes chrysocome chrysocome. Dive depth (mean + $\mathrm{SD}$ ) in relation to time of day for 520 randomly selected dives

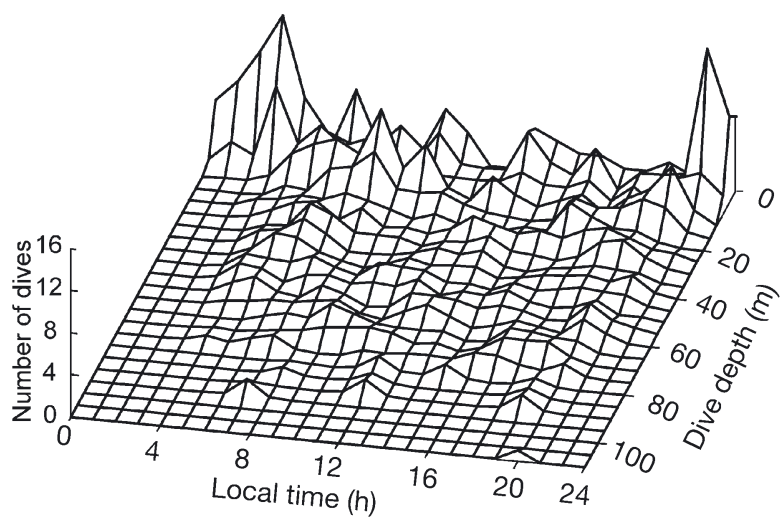

Fig. 4. Eudyptes chrysocome chrysocome. Distribution of number of dives in relation to time of day and dive depth for 520 randomly selected dives

by long dives (90 to $140 \mathrm{~s}$ ) at shallow depths (3 to $10 \mathrm{~m}$ ) were discarded for the analysis because of the software misinterpretation of several shallow dives (which were considered as 1 dive).

The penguins spent an average of $66.2 \pm 5.9 \%$ of the trip duration underwater, with no significant difference between day and night trips (Table 1) ( $t$-test: $t_{11}=$ $-1.86, \mathrm{p}=0.09$ ). Bottom time peaked at $34 \mathrm{~s}$ and averaged $35 \pm 17 \mathrm{~s}$ dive $^{-1}$, with $50 \%$ of the bottom times $\leq 33$ s. The penguins spent $37 \%$ of their diving time between depths of 0 and $20 \mathrm{~m}$. Diving efficiency averaged $0.34 \pm 0.14$, and its maximum was attained at dive depths between 5 and $15 \mathrm{~m}$ (Fig. 5b). The distribution of post-dive intervals was unimodal, with a peak at 14 to $24 \mathrm{~s}$, and with $50 \%$ of the post-dive intervals $\leq 19 \mathrm{~s}$. Excluding intervals $>180 \mathrm{~s}$, post-dive intervals aver- aged $20 \pm 11 \mathrm{~s}(\mathrm{n}=509)$. Rockhopper penguins traveled an average VTD of $43.88 \pm 22.78 \mathrm{~km}$ per foraging trip (excluding the incomplete trip). VTD differed between day and overnight trips (Table 1) ( $t$-test: $t_{11}=$ $-3.73, \mathrm{p}=0.003)$. The mean descent and ascent rates were $1.2 \pm 0.5 \mathrm{~m} \mathrm{~s}^{-1}$ and $0.8 \pm 0.5 \mathrm{~m} \mathrm{~s}^{-1}$ respectively. Both rates increased with increasing dive depth (descent rate $=0.85+0.01 \times$ depth, $F_{1,19}=57.35$; ascent rate $=0.78+0.01 \times$ depth, $F_{1,19}=85.26 ; \mathrm{p}<0.001$ for both). Descent rates tend to be larger than ascent rates ( $t$-test: $\left.t_{487}=47.9, \mathrm{p}<0.001\right)$.

\section{Temporal changes in foraging and diving behavior}

Taking into account the time elapsed from the start of hatching (November 27) to the middle of each trip, trip length increased significantly (trip length $=3.11 \times$ days $-17.41, \mathrm{r}^{2}=0.62, F_{1,12}=20.18, \mathrm{p}<0.001$, Fig. 6a), but the duration of both the outward and the inward trip did not vary ( $p$ of linear regression: $p=0.72$ and $p=0.10$
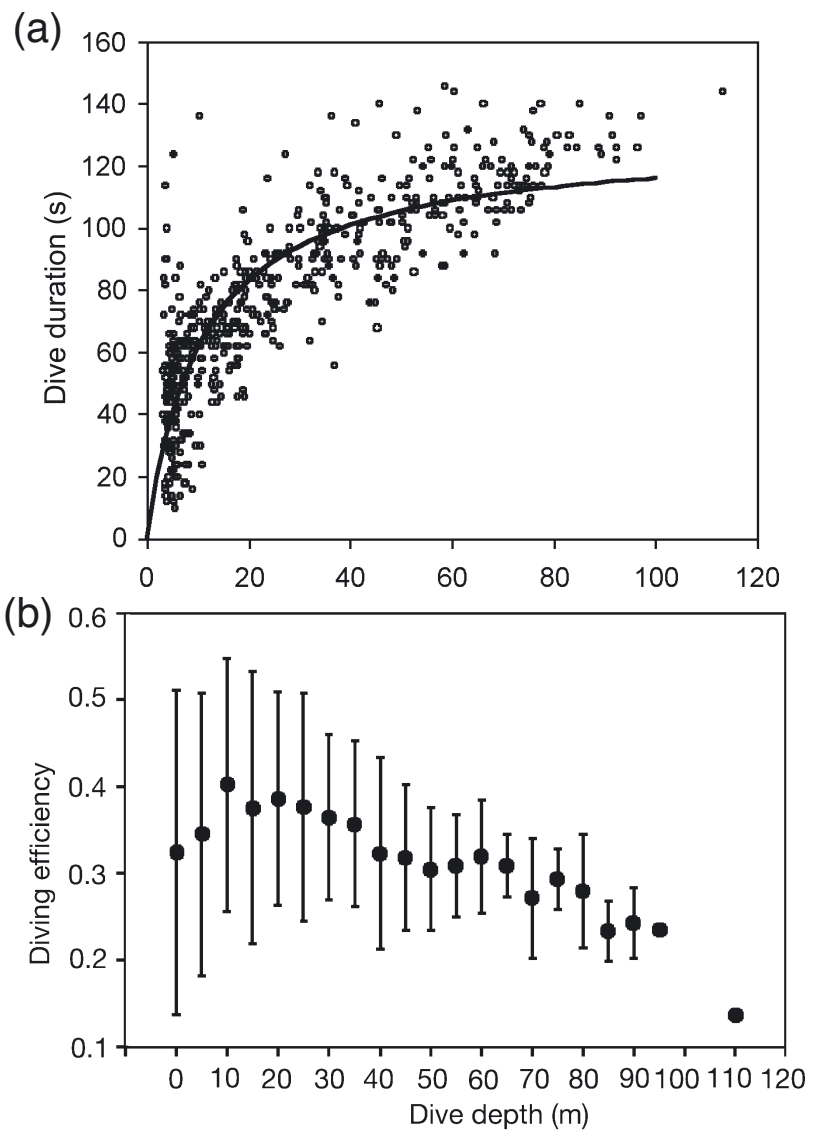

Fig. 5. Eudyptes chrysocome chrysocome. Relationship between (a) dive duration and dive depth, and (b) diving efficiency (bottom time/[dive duration + post-dive interval]) and dive depth (mean $\pm \mathrm{SD}$ ) for 520 randomly selected dives 

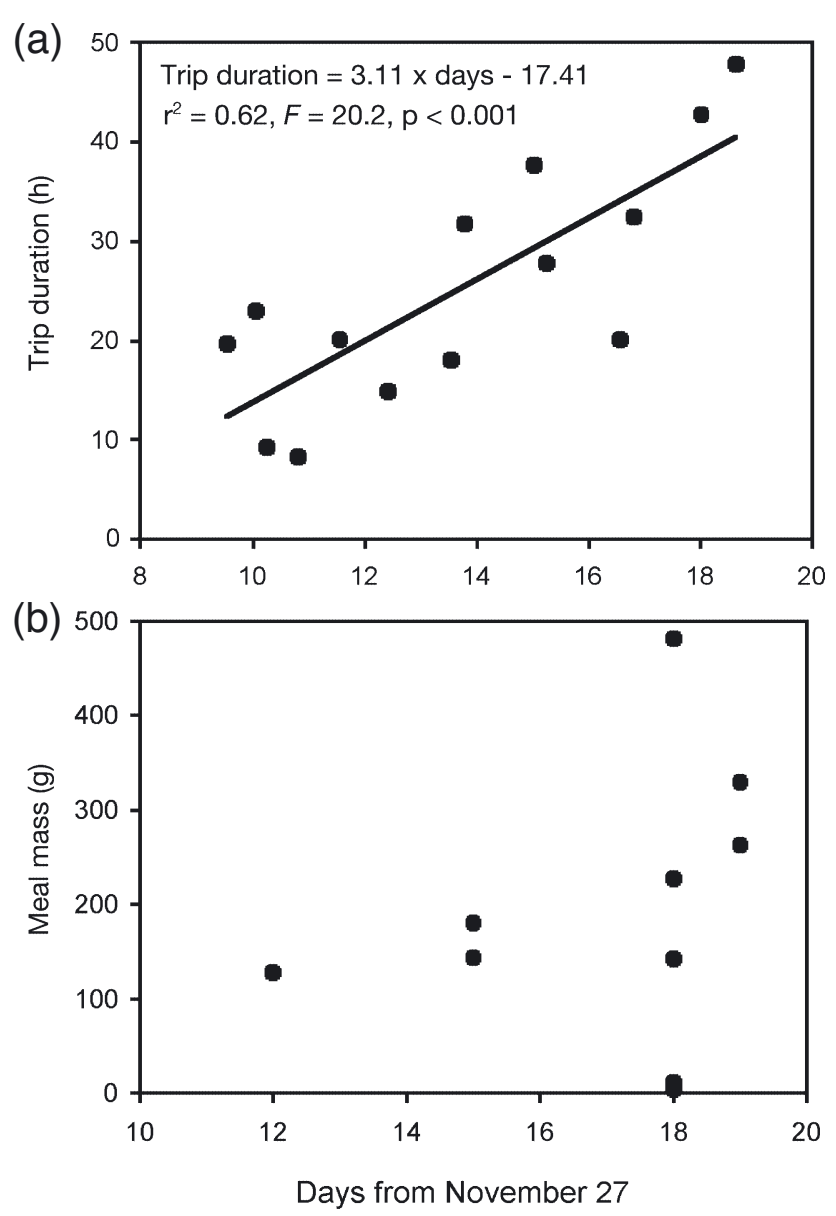

Fig. 6. Eudyptes chrysocome chrysocome. (a) Foraging trip duration in relation to days elapsed from start of hatching to the middle of the foraging trip; (b) mass of stomach content in relation to days elapsed from start of hatching

respectively). The basic dive parameters did not vary significantly for each trip over the study period ( $p$ of linear regression: $p>0.1$ for all except for ascent rate, which was $0.05>\mathrm{p}>0.04$ ). The mass of food brought ashore did not increase with time elapsed from the start of hatching (Fig. 6b) ( $p$ of linear regression: $p=0.34$ ).

\section{Diet composition}

The 11 stomach contents weighed $203.6 \pm 142.3 \mathrm{~g}$. On average, female rockhopper penguins brought ashore 5 to $10 \%$ of their body weight as food. No relationship was found between the mass of stomach contents and trip duration (linear regression ANOVA: $F_{1,2}$ $=0.19, \mathrm{p}=0.703)$. A total of 34139 prey items were found in the contents, comprising a mixture of crustaceans, cephalopods and fishes. Crustaceans dominated the diet in terms of numbers $(80 \%)$ followed by cephalopods and fishes (15 and 3.6\% respectively). However, cephalopods (mostly juveniles) contributed more to the diet in terms of mass (86\%) than crustaceans (14\%). Gonatus antarcticus dominated the diet in terms of mass (46\%), followed by Loligo gahi (24\%) and Enteroctopus megalocyathus (15\%). Among the crustaceans, Euphausia vallentini was the dominant prey item in terms of numbers (34\%), the amphipod Themisto gaudichaudii in terms of mass $(7 \%$ mass, $18.4 \%$ numbers), and Thysanoessa gregaria contributed less than $1 \%$ to the diet. Due to the lack of functional relationships for the fish larvae and juveniles in the diet, we could not reconstitute the mass consumed. Harpagifer bispinis was by far the most numerous fish consumed $(2.2 \%)$. There was a smaller proportion of Salilota australis (1.3\%), only a few specimens of Agonopsis chiloensis, and an unidentified myctophid.

\section{DISCUSSION}

\section{Foraging trips among subspecies and environments}

Our data reveals that chrysocome performed more overnight trips than the other subspecies (Table 1), and performed extended foraging trips with a wide dispersion of departure and arrival times, as well as short periods on land. The average trip duration for day and night trips is comparable among subspecies (Table 1), but much shorter than the $7.0 \pm 0.0 \mathrm{~d}(\mathrm{n}=6)$ or the $6.4 \pm$ $4.5 \mathrm{~d}(\mathrm{n}=7)$ reported by Hull (1999a and 2000 respectively) for female filholi during the guarding period at Macquarie Island. This trip duration is remarkable, as only the female feeds the chick during the guarding period. However, Hull (1999a) described that rockhopper penguins from Macquarie forage in the Polar Frontal Zone, which contains abundant or predictable food sources such as myctophid fishes, a common prey item of rockhooper penguins from Macquariem Island. Another explanation could be that some filholi females actually stayed on land during night and that this was undetected by the depth readings of the TDRs (in our study, the light-channel readings of our TDRs helped us to distinguish between periods on land and at sea). Finally, another explanation could be a strong device effect on the birds equipped at Macquarie Island that induced very long foraging trips.

It is known that penguins are visual predators that depend on ambient light to locate prey (Wilson et al. 1989, 1993), that they dive shallower at night than during the day, and that even when successful in catching prey, their foraging success at night is reduced (Wilson et al. 1993, Jansen et al. 1998). The performance of overnight foraging trips and dives has been recorded 
in several penguin species. Even in locations at a comparable latitude to Staten Island, penguins exhibit a variety of different foraging behavior. Rockhopper penguins breeding at Macquarie Island also dive at night, although the pooling of data precludes a detailed analysis (Hull 2000). At South Georgia, the king penguin Aptenodytes patagonica dives at night, but at much shallower depths than during the day (Kooyman et al. 1992). Female Macaroni penguins Eudyptes chrysolophus rearing chicks forage overnight, but at depths less than $20 \mathrm{~m}$ (Croxall et al. 1988). Gentoo penguins Pygoscelis papua, in which both parents feed the chick at brooding, forage only during the daytime (Croxall et al. 1988). At Signy Island, 26\% of the total foraging trips of chinstrap penguins Pygoscelis antarctica were overnight trips, with nighttime dives as frequent as daytime dives but reaching shallower depths (nighttime defined as time between sunset and sunrise: see Fig. $7 \mathrm{~b}$ of Takahashi et al. 2003). Royal penguins Eudyptes schlegeli from Macquarie Island dive both day and night, but at shallower depths at night (Hull 2000). In southern Chile, breeding Magellanic penguins Spheniscus magellanicus diving at night rarely dived deeper than $10 \mathrm{~m}$ (Radl \& Culik 1999). In Antarctica, Adelie penguins Pygoscelis adeliae from Torgersen Island showed a lack of a strong circadian pattern in dive depth (Chappell et al. 1993). Chinstrap penguins at Seal Island performed overnight trips to enable chicks to grow at an adequate rate (Jansen et al. 1998).

Successful hunting during darkness hours is related to the ambient light available as well as to the available prey in the water column. Few papers define the term 'nighttime' (for examples see Cherel et al. 1999 and Takahashi et al. 2003), assuming that night represents the time between sunset and sunrise, and disregarding the twilight period, important in high latitudes. Several explanations (nonmutually exclusive) may be proposed for the high proportion of overnight trips and dive frequency in the hours of darkness by female chrysocome compared with the other subspecies. These explanations may be related to the different body sizes of the different subspecies, to the daylight regime of a specific locality in the particular study period, to the size of the breeding population and/or to the environmental conditions that influence food availability in the area.

It is known that the foraging capacities of marine mammals and seabirds are related to body size (Kooyman \& Kooyman 1995, Schreer \& Kovacs 1997). Among rockhopper penguins, chrysocome is the smallest in size (Cooper et al. 1990). However, measurements of bill length $(38.3 \pm 2.0 \mathrm{~mm})$ and body weight $(2.3 \pm$ $0.2 \mathrm{~kg}$ ) obtained during the 2000 season in 45 females from Staten Island are in the range of those reported for moseleyi and filholi (Tremblay \& Cherel 2003) and do not allow any conclusion about a relationship between body size and foraging trip duration.

The lengths of the day and of the twilight period are a function of latitude and of time of the year. If foraging trip duration is just a function of day length, a relationship between location of breeding grounds and foraging trip duration would be expected. This was not the case for rockhopper penguins. Birds from Kerguelen Island (at about Latitude $49^{\circ} \mathrm{S}$ ) do not perform overnight trips whereas those from Amsterdam, Crozet, Marion, Macquarie and Staten Islands (at about Latitudes $38^{\circ} \mathrm{S}, 46^{\circ} \mathrm{S}, 49^{\circ} \mathrm{S}$ and $55^{\circ} \mathrm{S}$ respectively) do so (Brown 1987, Hull 1999a, 2000, Tremblay \& Cherel 2003, this paper). Moreover, trip duration represented 93,76 and $73 \%$ of the time between sunrise and sunset at Amsterdam, Kerguelen and Crozet respectively (Tremblay \& Cherel 2003). Therefore, there was still some time available for increasing foraging trip duration at Kerguelen and the Crozet Islands.

The proportion of the sampled dives performed under twilight conditions in Staten Island (23.3\%) and the proportion of foraging dives among the twilight dives (76\%) imply that chrysocome may experience ambient light conditions during the extended twilight period that are sufficient to continue foraging instead of returning to the colony. This supposition is reinforced by their high dive rate and by the large proportion of time spent underwater for overnight trips compared to moseleyi and filholi (Table 1). This finding emphasizes the need to analyze diving under twilight conditions at high-latitude locations since, for chrysocome, it seems that during the brooding period they have almost permanent light conditions in which to forage.

Another potential explanation for the long trip duration is that foraging trip characteristics are related to colony size. As mentioned in the 'Introduction', the distance to the foraging grounds or trip duration should be proportional to the breeding population size. This would be reflected either in the proportion of overnight trips, in the foraging trip duration or traveling time and/or in the proportion of traveling versus foraging behavior. The available evidence suggests that none of these features may be related to colony size. The proportion of overnight trips recorded at Amsterdam, Crozet, Kerguelen and Staten Islands, 11, 10, 0 and $53 \%$ respectively (Tremblay \& Cherel 2003, this paper) do not correlate with colony sizes of 24890 , 60000,85500 , and 174000 breeding pairs respectively (Pearson correlation coefficient $=0.86, \mathrm{p}=0.35$ ) $($ data from Woehler 1993, Guinard et al. 1998, Schiavini 2000). The population size at Macquarie Island is reported to be between 100000 and 500000 pairs and for that reason was not considered in this analysis. On the other hand, the large variation in traveling times 
and trip duration among rockhopper subspecies precludes a conclusion about any relationship with colony size (Table 1). Finally, the mean proportion of foraging dives in chrysocome (>5 m depth, $89.9 \pm 3.8 \%$ ) was comparable with that reported for Amsterdam, Crozet and Kerguelen Islands $(79.6 \pm 11.7,86.1 \pm 12.7,85.0 \pm$ $13.3 \%$ respectively, Tremblay \& Cherel 2003).

A complementary explanation relates to the environment. Tremblay \& Cherel (2003) compared characteristics of foraging trips of rockhopper penguins from Amsterdam, Crozet and Kerguelen and proposed that penguins foraging in more open waters (at Amsterdam and Crozet), perform some overnight trips, whereas those foraging in coastal waters at Kerguelen do not (birds breeding at Kerguelen forage in shallow and sheltered waters in the Gulf of Morbihan: Tremblay \& Cherel 2003). In turn, filholi females from Macquarie Island foraged on oceanic waters of the Polar Frontal Zone for periods of $7.0 \pm 0.0 \mathrm{~d}$ when guarding chicks (Hull 1999a) and also performed overnight trips. Birds from Staten Island foraged as far away as $20 \mathrm{~km}$ from the colony, in shelf waters of 100 to $200 \mathrm{~m}$ depth, but also in more pelagic waters of a shelf-break and slope located $12 \mathrm{~km}$ south of Staten Island. The foraging trip duration of chrysocome, which is able to feed either in shelf or in pelagic waters, may represent furhter evidence of phenotypic plasticity in response to different marine environments, as reported for the other subspecies by Tremblay \& Cherel (2003).

The dietary data also suggest that chrysocome may forage either in shelf waters or in more pelagic waters off the shelf. The food mass brought ashore by the penguins at Staten Island $(203.6 \pm 142.3 \mathrm{~g})$ is larger than that sampled from birds foraging in more open waters at Amsterdam and Crozet Islands $(107.5 \pm 47.5$ and $150.6 \pm 50.5 \mathrm{~g}$ respectively), but more similar to that at Kerguelen Island $(214.8 \pm 62.3 \mathrm{~g}$, Tremblay \& Cherel 2003). This suggests that foraging on shelf habitats (at Kerguelen and Staten Island) could be more productive than foraging in open waters (at Amsterdam or Crozet Islands). The large standard deviation of the mass obtained at Staten Island may be also a consequence of foraging either in shelf waters or in more open waters off the shelf. Southern rockhopper penguins at Staten Island feed opportunistically on shoaling or swarming zooplanktonic prey, as reported elsewhere (Croxall et al. 1985, Horne 1985, Brown \& Klages 1987, Hindell 1988, Klages et al. 1988, 1989, Cooper et al. 1990, Hull 1999b, Pütz et al. 2001, Clausen \& Pütz 2002). Gregarious crustaceans, juvenile squid and octopus, fish larvae and juveniles dominated the diet. The crustaceans in the diet are associated with subantarctic waters, although Themisto gaudichaudii is present also in antarctic waters (Vinogradov 1999). These crustaceans form interspecific swarms or swarms within close vicinity to each other (Dadon \& Boltovskoy 1982, Tarling et al. 1995). All are found in depths down to $100 \mathrm{~m}$ and are known to migrate vertically to the surface at night (Gibbons et al. 1999). The most common cephalopods consumed are known to be mid- to deep-water species present in the Subantarctic Zone (Rodhouse et al. 1992, 1996). Small specimens of Gonatus antarcticus were found in great numbers in the Polar Frontal Zone (Rodhouse et al. 1992), and the same study found that early life cycles of cephalopods (paralarvae and juveniles) are associated with major oceanographic features of the SW Atlantic Ocean. Salilota australis and Sprattus fuegensis inhabit the Patagonian shelf and are associated with the Falkland (Malvinas) Current. Moreover, Ehrlich et al. (1999) found densities of 102 to 1000 and 11 to 100 larvae $10 \mathrm{~m}^{-2}$ of $S$. fuegensis and Agonopsis chiloensis respectively around Staten Island.

The wide shelf waters of the southern Patagonian shelf sustain an important biomass of zooplankton and ichthyoplankton (Sánchez \& Ciechomski 1995, Sabatini et al. 1999, 2001). The combined effect of diurnal vertical migration and advection of zooplankton due to the transition of bottom topography from the shelf slope to the shelf areas may contribute to the food availability for top predators. Perissinotto \& McQuaid (1992) described such phenomena for the Prince Edwards archipelago, where large levels of zooplankton, migrating to the surface at night, become available to visual top predators such as seabirds. A similar phenomena may occur at Staten Island, with the shelf and slope located very close to penguin breeding grounds, and upstream of the branch of the Antarctic Circumpolar Current that enters the Patagonian shelf after leaving the Drake Passage to form the Falklands (Malvinas) Current. The macrozooplankton that rises in the water column during the long periods of dusk and dawn would be available for visual predators such as penguins. The zooplankton availability combined with the extended twilight periods in summer, may differentiate the marine environment close to Staten Island from that of Amsterdam, Crozet, Kerguelen and the Macquarie Islands.

\section{Diving patterns}

Most dive parameters for chrysocome (such as average maximum dive depth, dive duration, bottom time, descent and ascent rate) were comparable to those for the other subspecies (Table 1). The deepest dive among the 15 trips was $113 \mathrm{~m}$ and averaged $81.5 \pm$ $18.5 \mathrm{~m}$, being comparable among subspecies: $66 \mathrm{~m}$ for filholi at Crozet (Wilson et al. 1997b), $66 \pm 28 \mathrm{~m}$ and $109 \mathrm{~m}$ for moseleyi at Amsterdam (Tremblay et al. 
1997, Cherel et al. 1999, and this study Table 1). On the other hand, chrysocome presented a more even depth utilization than the other subspecies (Cherel et al. 1999, Hull 2000, Tremblay \& Cherel 2003). The deepest dives by chrysocome were performed at noon, as reported for moseleyi (Cherel et al. 1999, Tremblay \& Cherel 2003). Our data on dive depth and dive duration confirms that, for rockhopper penguins, as for the other subspecies (Wilson et al. 1997b, Cherel et al. 1999, Tremblay \& Cherel 2003) most dives do not exceed the aerobic dive limit (sensu Chappel et al. 1993).

Eudyptes chrysocome spent almost $2 / 3$ of its foraging trips underwater, a proportion comparable to that of the other subspecies (Table 1) but larger than that reported for most other penguin species (Table 1 of Cherel et al. 1999 and references cited therein) and even for other top predators (Schreer et al. 2001). As Cherel et al. (1999) pointed out, the long time spent underwater is due mainly to the high dive rate of rockhopper penguins. Also, as one of the smallest penguin species, the size of its prey is limited by the size of its mouth, which is reflected in its diet. Therefore, rockhopper penguins need to develop a high dive rate in order to compensate for the capture of small prey. The distribution of diving efficiency with depth (Fig. 5a) reveals that chrysocome attains lower efficiencies for a given depth than do moseleyi and filholi (cf. present Fig. 5 with Fig. 7 of Tremblay \& Cherel 2003), although this may be a characteristic of use of the water column rather than a physiological difference. The large average VTD per foraging trip for chrysocome in relation to moseleyi and filholi (Table 1) is readily explained by the former's homogeneous use of the water column and by the extended trip duration.

\section{Rockhopper penguins foraging and breeding at Staten Island}

Analysis of all the data on foraging trips and dive characteristics reveals that chrysocome differs from the other subspecies only in the extent of its foraging trips, with the other basic dive parameters being comparable. Our results confirm that rockhopper penguins from locations with different daylight and twilight periods share a high level of foraging effort, due to their high dive rate and percentage of time spent underwater, as pointed out by Cherel et al. (1999). This high effort is also consistent with the amount of food brought ashore at different localities. We conclude that an increase in the daylight period implies an increase in trip duration, but not in a reduction of foraging effort. Therefore, light would seem to be the main limiting factor of foraging behavior in rockhopper penguins. An exception could be the population at
Macquarie Island, with a daylight period similar to that at Staten Island, where Hull (2000) found dive rates of $14.8 \pm 9.4$ dives $\mathrm{h}^{-1}$. The difference could be due to either differences in food availability and/or to an overestimation of trip duration caused by periods on land undetected from TDR readings.

During the study period, foraging trip duration increased in chrysocome, but the amount of food brought back to the colony did not (Fig. 6). However, chick age was not recorded when obtaining stomach contents and the variation in Fig. 6 could be due to some unknown dietary variation related to chick age. Based on trip duration and the outward and inward traveling times, chrysocome foraged for longer periods than the other subspecies with the exception of filholi from Macquarie Island. This supports the proposal of Cherel et al. (1999), who suggested that in view of the overall foraging and diving behavior of moseleyi, the only characteristic of foraging behavior most likely to vary in relation to energy demand and/or prey availability would be the duration of foraging trips.

Rockhopper penguins constitute the main diving seabird breeding at Staten Island, together with the Magellanic penguin Spheniscus magellanicus with ca. 100000 nesting pairs (Schiavini et al. 1999). The nearest rockhopper penguin colonies are at the southern tip of the Tierra del Fuego archipelago or in the Falkland (Malvinas) Islands, far away from the foraging range of Staten Island birds during the brooding period. The diet of the Magellanic penguin in the southern SW Atlantic Ocean differs from the rockhopper penguin diet, because it includes fuegian sardine Sprattus fuegensis, southern blue whiting Micromesistius australis, silverside Austroatherina sp., Patagonian squid Loligo gahi and lobster krill Munida sp., with proportions varying according to location (Thompson 1993, Frere et al. 1996). Therefore, rockhopper penguins from Staten Island do not seem to compete for food with other penguins.

However, the large population of 167000 breeding pairs at Bahía Franklin and the restricted foraging ranges of brooding females imply that foraging effort is confined to a relatively small area and time. This is emphasized by the fact that outward and inward traveling times (and thus foraging range) do not increase as the brooding period progresses. The question arises as to whether such a breeding population may compete for feeding space. It can be hypothesized that a combination of an extended twilight period and the plentiful food supply in shelf waters, which in turn is enhanced by the availability of zooplankton resulting from diurnal vertical migrations, may offer rockhopper penguins an extended time to exploit abundant food resources compared to other subspecies. This extra resource time may contribute indirectly to reduce 
potential intraspecific competition. In order to test this hypothesis, our study would need to be repeated for other colonies of different sizes, located in similar areas of southern South America but in different environments, e.g. on more oceanic islands such as Islas Diego Ramírez or Isla Noir in the Pacific Ocean.

The large time-window for exploiting food resources available to rockhopper penguins may contribute to sustaining the high level of the breeding population in this area, and may also contribute to understanding differences in the recent history of the breeding colonies in the Falklands Islands and from Staten Island, whereby the former have undergone strong declines and recoveries during the last century (Bingham 1998, Pütz et al. 2001), while the latter appear to have been stable or increasing (Schiavini 2000).

Acknowledgements. This research was possible with the support of the Consejo Nacional de Investigaciones Científicas y Técnicas (CONICET), the Third World Academy of Sciences (Grant No. 99-193 RG/BIO/LAA to A.S.), the International Foundation for Science (grant A/2962-1 to A.S.), and of R. Portal (Total Austral SA). Special thanks to the Argentine Navy and to P. Grinberg for their transportation to Staten Island under difficult weather conditions, to P. Pérez Barros and M. Liljesthröm for their help in the field and with the English writing, to J. Lage, for arranging Multitrace to fit our needs, to R. Wilson for his advice on TDRs and software, and to K. Pütz, Y. Cherel, T. Martin and P. Trathan for their kind feedback.

\section{LITERATURE CITED}

Ashmole NP (1963) The regulation of numbers of tropical oceanic birds. Ibis 103:458-473

Bertolotti MI, Brunetti NE, Carreto JI, Prenzki LB, Sánchez RP (1996) Influence of shelf-break fronts on shellfish and fish stocks off Argentina, Theme Session S. ICES, Copenhagen

Bingham M (1998) The distribution, abundance and population trends of gentoo, rockhopper and king penguins in the Falkland Islands. Oryx 32:223-232

Brown CR (1987) Traveling speed and foraging range of macaroni and rockhopper penguins at Marion Islands. J Field Ornithol 58:118-125

Brown CR, Klages NT (1987) Seasonal and annual variation in diets of macaroni Eudyptes chrysolophus chrysolophus and southern rockhopper E. chrysocome chrysocome penguins at sub-Antarctic Marion Island. J Zool 212:7-28

Cairns DK (1989) The regulation of seabird colony size: a hinterland model. Am Nat 134:141-146

Chappel MA, Shoemaker VH, Janes DN, Bucher TL (1993) Diving behavior during foraging in breeding Adelie penguin. Ecology 74:1204-1215

Cherel Y, Tremblay Y, Guinard E, Georges JY (1999) Diving behavior of female northern rockhopper penguins, Eudyptes chrysocome moseleyi, during the brooding period at Amsterdam Island (Southern Indian Ocean). Mar Biol 134:375-385

Clarke MR (1986) A handbook for the identification of cephalopod beaks. Clarendon Press, Oxford

Clausen AP, Putz K (2002) Recent trends in diet composition and productivity of gentoo, magellanic and rockhopper penguins in the Falkland Islands. Aquat Conserv 12:51-61
Cooper J, Brown CR, Gales RP, Hindell MA and 6 others (1990) Diets and dietary segregation of crested penguins (Eudyptes). In: Davis LS, Darby JT (eds) Penguin biology. Academic Press, London, p 131-156

Croxall JP (1984) Seabirds. In: Laws RM (ed) Antarctic ecology. Academic Press, London, p 534-616

Croxall JP, Lishman GS (1987) The food and feeding ecology of penguins. In: Croxall JP (ed) Seabirds: feeding ecology and role in marine ecosystems. Cambridge University Press, Cambridge, p 101-133

Croxall JP, Prince PA, Baird A, Ward P (1985) The diet of the southern rockhopper penguin Eudyptes chrysocome at Beauchene Island, Falkland Islands. J Zool 206:485-496

Croxall JP, Davis RW, O'Connell MJ (1988) Diving patterns in relation to diet of gentoo and macaroni penguins at South Georgia. Condor 90:157-167

Dadon JR, Boltovskoy D (1982) Zooplanctonic recurrent groups (Pteropoda, Euphausiacea, Chaetognatha) in the SW Atlantic ocean. Physis A 41(100):63-83

Duffy DC, Jackson S (1986) Diet studies of seabirds: a review of methods. Colon Waterbirds 9:1-17

Ehrlich MD, Sánchez RP, Ciechomski JD (1999) Ichthyoplankton composition, distribution and abundance on the southern Patagonian shelf and adjacent waters. Instituto Nacional de Investigacion y Desarrollo Pesquero, Documento Cientifico No. 5. Mar del Plata, Argentina, p 37-65

Ellis S, Croxall JP, Cooper J (eds) (1998) Penguin conservation assessment and management plan. Rep IUCN/SSC. Conservation Breeding Specialist Group, Apple Valley, MN

Frere E, Gandini P, Lichtschein V (1996) Variación latitudinal en la dieta del Pingüino de magallanes (Spheniscus magellanicus) en la costa Patagónica, Argentina. Ornitol Neotrop 7:35-41

Gibbons MJ, Spiridonov VA, Tarling GS (1999) Euphausiacea. In: Boltovskoy D (ed) South Atlantic zooplankton. Backhuys, Leiden, p 1241-1279

González AF, Trathan PN, Yau C, Rodhouse PG (1997) Interactions between oceanography, ecology and fishery biology of the ommastrephid squid Martialia hyadesi in the South Atlantic. Mar Ecol Prog Ser 152:205-215

Guinard E, Weimerskirch H, Jouventin P (1998) Population changes and demography of the northern rockhopper penguin on Amsterdam and Saint Paul Islands. Colon Waterbirds 21:222-228

Hindell MA (1988) The diet of the rockhopper penguin Eudyptes chrysocome at Macquarie Island. Emu 88: 227-233

Horne RSC (1985) Diet of royal and rockhopper penguins at Maquarie Island. Emu 85:150-156

Horning M, Trillmich F (1997) Ontogeny of diving behavior in the Galapagos fur seal. Behaviour 134:1211-1257

Hull CL (1999a) The foraging zones of breeding Royal (Eudyptes schlegeli) and rockhopper (E. chrysocome) penguins: an assessment of techniques and species comparison. Wildl Res 26:789-803

Hull CL (1999b) Comparison of the diets of breeding royal (Eudyptes schlegeli) and rockhopper (Eudyptes chrysocome) penguins on Macquarie Island over three years. J Zool 247:507-529

Hull CL (2000) Comparative diving behavior and segregation of the marine habitat by breeding royal penguins, Eudyptes schlegeli, and eastern rockhopper penguins, Eudyptes chrysocome filholi, at Macquarie Island. Can J Zool 78:333-345

Hurlbert SH (1984) Pseudoreplication and the design of ecological field experiments. Ecol Monogr 54:187-211

Hyslop EJ (1980) Stomach contents analysis-a review of 
methods and their application. J Fish Biol 17:411-429

Jansen JK, Boveng PL, Bengtson JL (1998) Foraging modes of chinstrap penguins: contrasts between day and night. Mar Ecol Prog Ser 165:161-172

Klages NT, Brooke MDL, Watkins BP (1988) Prey of northern rockhopper penguins at Gough Island, South Atlantic Ocean. Ostrich 59:162-165

Klages NT, Gales RP, Pemberton D (1989) Dietary segregation of macaroni and rockhopper penguins at Heard Island. Wildl Res 16:599-604

Kooyman GL, Kooyman TG (1995) Diving behavior of emperor penguins nurturing chicks at Coulman Island, Antarctica. Condor 97:536-549

Kooyman GL, Cherel Y, Le Maho Y, Croxall JP, Thorson PH, Ridoux V, Kooyman CA (1992) Diving behavior and energetics during foraging cycles in king penguins. Ecol Monogr 32:143-163

Orsi A, Whitworth III T, Nowli WD (1995) On the meridional extent of the Antarctic Circumpolar Current. Deep-Sea Res I 42:641-673

Parker G, Paterlini MC, Violante RA (1997) El fondo marino. In: Boschi EE (ed) El Mar Argentino y sus recursos pesqueros. Tomo 1. Antecedentes históricos de las exploraciones en el mar y las características ambientales. Instituto Nacional de Investigación y Desarrollo Pesquero, Mar del Plata, p 65-88

Perissinotto R, McQuaid CD (1992) Land-based predator impact on vertically migrating zooplancton and micronecton advected to a Southern Ocean archipelago. Mar Ecol Prog Ser 80:15-27

Piola AR, Rivas AL (1997) Corrientes en la plataforma continental. In: Boschi EE (ed) El Mar Argentino y sus recursos pesqueros. Tomo 1. Antecedentes históricos de las exploraciones en el mar y las características ambientales. Instituto Nacional de Investigación y Desarrollo Pesquero, Mar del Plata, p 119-132

Pütz K, Ingham RJ, Smith JG, Croxall JP (2001) Population trends, breeding success and diet composition of gentoo Pygoscelis papua, magellanic Spheniscus magellanicus and rockhopper Eudyptes chrysocome penguins in the Falkland Islands. Polar Biol 24:793-807

Radl A, Culik BM (1999) Foraging behavior and reproductive success in magellanic penguins (Spheniscus magellanicus): a comparative study of two colonies in southern Chile. Mar Biol 133:381-393

Ridoux V (1994) The diets and dietary segregation of seabirds at the subantarctic Crozet Islands. Mar Ornithol 22:1-192

Rodhouse PG, Symon C, Hatfield EMC (1992) Early life cycle of cephalopods in relation to the major oceanographic features of the southwest Atlantic Ocean. Mar Ecol Prog Ser 89:183-195

Rodhouse PG, Prince PA, Trathan PN, Hatfield EMC, Watkins JL, Bone DG, Murphy EJ, White MG (1996) Cephalopods and mesoscale oceanography at the Antarctic Polar Front: satellite tracked predators locate pelagic trophic interactions. Mar Ecol Prog Ser 136:37-50

Sabatini ME, Alvarez Colombo GL (2001) Seasonal pattern of zooplankton biomass in the Argentinian shelf off Southern Patagonia $\left(45^{\circ}-55^{\circ} \mathrm{S}\right)$. Sci Mar 65:21-31

Sabatini ME, Alvarez Colombo GL, Ramírez F (1999) Zooplankton biomass in the reproductive area of the southern blue whiting (Micromesistius australis). Instituto Nacional de Investigacion y Desarrollo Pesquero, Documento Cientifico No. 5. Mar del Plata, Argentina, p 23-35

Sánchez RP, Ciechomski JD de (1995) Spawning and nursery grounds of pelagic fish species in the sea-shelf off Argentina and adjacent areas. Sci Mar 59:455-478
Sánchez RP, Remeslo A, Madirolas A, Ciechomski JD de (1995) Distribution and abundance of post-larvae and juveniles of the Patagonian sprat, (Sprattus fuegensis), and related hydrographic conditions. Fish Res 23:47-81

Schiavini ACM (2000) Staten Island, Tierra del Fuego: the largest breeding ground for southern rockhopper penguins? Waterbirds 23(2):286-291

Schiavini ACM, Frere E, Yorio P, Parera A (1999) Las aves marinas de la Isla de los Estados, Tierra del Fuego, Argentina: revisión histórica, estado poblacional y problemas de conservación. An Ins Patagonia 27:25-40

Schreer JF, Kovacs KM (1997) Allometry of diving capacity in air-breathing vertebrates. Can J Zool 75:339-358

Schreer JF, Kovacs KM, O'Hara Hines RJ (2001) Comparative diving patterns of pinnipeds and seabirds. Ecol Monogr 71:137-162

Servicio de Hidrografía Naval (1993) Carta H-148: Isla de los Estados. Estrecho Le Maire, Servicio de Hidrografía Naval, Buenos Aires

Takahashi A, Dunn MJ, Trathan PN, Sato K, Naito Y, Croxall JP (2003) Foraging strategies of chinstrap penguins at Signy Island, Antarctica: importance of benthic feeding on Antarctic krill. Mar Ecol Prog Ser 250:279-289

Tarling GA, Ward P, Sheader M, Williams JA, Symon C (1995) Distribution patterns of macrozooplancton assemblages in the southwest Atlantic. Mar Ecol Prog Ser 120:29-40

Thompson KR (1993) Variation in magellanic penguin Spheniscus magellanicus diet in the Falkland Islands. Mar Ornithol 21:57-67

Tremblay Y, Cherel Y (1999) Synchronous underwater foraging behavior in penguins. Condor 101:179-185

Tremblay Y, Cherel Y (2000) Benthic and pelagic dives: a new foraging behavior in rockhopper penguins. Mar Ecol Prog Ser 204:257-267

Tremblay Y, Cherel Y (2003) Geographic variation in the foraging behavior, diet and chick growth of rockhopper penguins. Mar Ecol Prog Ser 251:279-297

Tremblay Y, Guinard E, Cherel Y (1997) Maximum diving depths of northern rockhopper penguins (Eudyptes chrysocome moseleyi) at Amsterdam Island. Polar Biol 17: $119-122$

Vinogradov G (1999) Amphipoda. In: Boltovskoy D (ed) South Atlantic zooplankton. Backhuys, Leiden, p 1141-1240

Wilson R (1984) An improved stomach pump for penguins and other seabirds. J Field Ornithol 55:110-112

Wilson RP, Culik B, Coria NR, Adelung D, Spairani HJ (1989) Foraging rhythms in Adélie penguins (Pygoscelis adeliae) at Hope Bay, Antarctica; determination and control. Polar Biol 10:161-165

Wilson RP, Pütz K, Bost CA, Culik BM, Bannasch R, Reins T, Adelung D (1993) Diel dive depth in penguins in relation to diel vertical migration of prey: whose dinner by candlelight? Mar Ecol Prog Ser 94:101-104

Wilson RP, Pütz K, Peters G, Culik B, Scolaro JA, Charrassin JB, Ropert-Coudert Y (1997a) Long-term attachment of transmitting and recording devices to penguins and other seabirds. Wild Soc Bull 25:101-106

Wilson RP, Bost CA, Pütz K, Charrassin JB, Culik BM, Adelung D (1997b) Southern rockhopper penguin Eudyptes chrysocome chrysocome foraging at Possession Island. Polar Biol 17:323-329

Woehler EJ (1993) The distribution and abundance of Antarctic and subantarctic penguins. Scientific Committee on Antarctic Research, Cambridge

Ydenberg RC, Clark CW (1989) Aerobiosis and anaerobiosis during diving by western grebes: an optimal foraging approach. J Theor Biol 139:437-449 